\section{Policy implications}

The aim of our research is to raise awareness of mythology in drug advertising, which may lead to doctors being better able to resist misleading promotion. This implies a need for closer regulation of journals as a privileged channel of communication from the drug industry to clinicians. It also highlights a rhetorical mode of persuasion in contrast with rational argument. By recognising that clinicians are also consumers, researchers and regulators could learn from advertisers how to change beliefs and behaviour more effectively than by reason alone. ${ }^{19}$

We thank Iain Chalmers and Barbara Mintzes for supporting the idea of this study, staff and students at the University of California School of Public Health and the University of St Andrews School of Management for comments on seminar presentations of the study, Iain Munro for theoretical advice, Alan Chandler and Peter Mansfield for suggested revisions to earlier drafts, and colleagues at the University of York for support and encouragement.

Contributors: TS was responsible for the conception, design, establishment, analysis, and writing up of the study. NS contributed to the conception, design, establishment, analysis, and writing. DRT contributed to the design and establishment, analysis, and writing.

Funding: The study was funded by a grant from the University of York Innovation Fund supplemented by the Department of Health Sciences. Some of TS's work was done during a Harkness Fellowship in Health Policy 2002-3, awarded by the Commonwealth Fund of New York.

Competing interests: None declared.
1 Lexchin J, Mansfield P, Mintzes B, Medawar C, Hamdan Z. Drug promotion database: WHO Department of Essential Drugs and Medicines Policy, Health Action International Europe, Universiti Sains Malaysia. www.drugpromo.info/ (updated 2002, accessed 2 Nov 2004).

2 Mansfield PR. Healthy Skepticism's new AdWatch: understanding drug promotion. Med J Aust 2003;179:644-5.

3 Sutherland M. Advertising and the mind of the consumer: what works, what doesn't and why. Sydney: Allen and Unwin, 1993.

4 Mansfield PR. Classifying improvements to drug marketing and justifications for claims of efficacy. Int J Risk Safety Med 1991;2:171-84.

5 Wade V, Mansfield PR, McDonald P. Drug companies evidence to justify advertising. Lancet 1989;ii:1261-3.

6 Wilkes MS, Doblin BH, Shapiro M. Pharmaceutical advertisements in leading medical journals: experts' assessments. Ann Intern Med 1992;116:912-9

7 Goldman R, Montagne M. Marketing "mind mechanics": decoding antidepressant advertisements. Soc Sci Med 1986;22:1047-58.

8 Hutcheon L, Hutcheon M. Medical "mythologies": a semiotic approach to pharmaceutical advertising. Queen's Q 1987;94:904-16.

9 Mansfield PR. Garai's challenge: the 40th anniversary of the inspiration for Healthy Skepticism. Healthy Skepticism International News 2003;1:10 (www.healthyskepticism.org/editions/2003/10.asp).

10 Morgan S, Barer M, Evans R. Health economists meet the fourth tempter: drug dependency and scientific discourse. Health Econ 2000;9:659-67.

11 Scott D, Ferner R. "The strategy of desire" and rational prescribing. $\mathrm{Br} \mathrm{J}$ Clin Pharmacol 1994;37:217-9.

12 Stimson GV. The message of psychotropic drug ads. Journal of Communications 1975;25:153-60.

13 Baudrillard J. La Societe de Consommation. Paris: Gallimard, 1970.

14 Saussure F de. Course in general linguistics. London: Duckworth, 1983.

15 Barthes R. Mythologies. London: Vintage, 1972/1957.

16 Derrida J. Dissemination. Chicago: University of Chicago, 1981

17 Farrell L. Ads: O Liberty! what crimes are committed in thy name! $B M J$ 2000;321:578.

18 Sontag S. Illness as a metaphor and AIDS and its metaphors. London: Penguin, 1991.

19 Landgren F, Harvey K, Mashford M, Moulds R, Guthrie B, Hemming M. Changing antibiotic prescribing by educational marketing. Med J Aust 1988;149:595-9.

\title{
Commentary: Accepting what we can learn from advertising's mirror of desire
}

Peter Mansfield

\begin{abstract}
'Now can you think what the Mirror of Erised shows us all?'. .

Harry thought. Then he said slowly, 'It shows us what we want ... whatever we want...

'Yes and no,' said Dumbledore quietly. 'It shows us nothing more or less than the deepest, most desperate desire of our hearts.'
\end{abstract}

J K Rowling, Harry Potter and the Philosopher's Stone

The commercial success of the Harry Potter books, despite literary limitations, shows both the power of promotion and the power of imagery that taps deeper meanings from metaphors and ancient myths. Readers of the first Harry Potter book are challenged to decode the inscription on the magical Mirror of Erised to reveal the meaning: "I show not your face but your heart's desire." Drug advertising is also a mirror to our souls that can teach us much about ourselves. ${ }^{2}$ Competition among drug companies to increase sales creates selective pressure for the evolution of advertising that accurately reflects how healthcare professionals really make decisions. Scott and colleagues have decoded advertising's mirror of desire. ${ }^{13}$ We may not want to believe what the mirror shows us, nor agree with the details of their decoding, but acceptance of their main messages may lead to major improvements in medical decision making by reducing our vulnerability to adverse influence.

Many healthcare professionals deny that we are influenced by drug promotion because to admit other- wise would insult our intelligence ${ }^{3}$ and hurt our self esteem. Some of us concede that some of our peers are vulnerable, but not ourselves. By contrast, drug companies know that combinations of promotional techniques, including carefully chosen images that appeal to our desires, are effective for increasing sales. ${ }^{4}$ Images influence even the cleverest people by sneaking in under the radar of our verbal intelligence. ${ }^{2}$ The first step to overcoming this vulnerability is to dispel our illusion of invulnerability by accepting that we all have human limitations. ${ }^{5}$

Many of us have been misled into overconfidence about drugs such as cyclo-oxygenase- 2 inhibitors, antidepressants, and misnamed "hormone replacement therapy." To avoid being misled again and again, we need a better understanding of how promotional techniques work as a foundation both for better regulation of promotion and for better training for healthcare professionals. ${ }^{6}$ Harnessing promotional techniques may also enable more effective dissemination of evidence based medicine. My informal marketing research suggests that the metaphors in this commentary will work like magic for many readers but not for all.

Scott et al's article helps us by studying how symbols and signs in advertising images can create powerful meanings by tapping into the myths we use to understand our world, our lives, and ourselves. Images
Healthy Skepticism, 34 Methodist Street, Willunga, $5172 \mathrm{SA}$, Australia Peter Mansfield director

peter@ healthyskepticism.org 
have different meanings for different people, depending on many factors, including culture and roles. Because images are rarely examined carefully with verbal thought, we are seldom fully aware of the meanings that are generated. The various meanings received by healthcare professionals may differ from the meanings intended by the advertisers. Advertisers hardly ever tell us what messages they intend to send because doing so can break the spell they are casting. However, Ogilvy (founder of the famous advertising agency) disclosed that some of his most powerful images came from his dreams and asserted that "Good ideas come from the unconscious." " He did not claim to fully understand what his images meant. What mattered to him was that they were effective for increasing sales.

Research on the range of meanings that healthcare professionals receive from superficial but repeated exposure to drug advertisements and the influence on prescribing deserves priority. Meanwhile this article shows what meanings can be decoded by a small team thinking about images in great depth. We may not all follow them that far, but medical decision making is likely to improve if we accept the desirability of becoming more thoughtful about advertising. Now, can you think what advertising's mirror of desire shows you?

\footnotetext{
Scott T, Stanford N, Thompson DR. Killing me softly: myth in pharmaceutical advertising. BMJ 2004:329;1484-7.

Mansfield PR. Healthy Skepticism's new AdWatch: understanding drug promotion. Med J Aust 2003;179:644-5.

promotion. Med A Aust 2003, $179.644-5$.

Black H. Dealing in drugs. Lancet 2004,364:1655-6.

Scott DK, Ferner RE. "The strategy of desire" and rational prescribing. $\mathrm{Br}$ J Clin Pharmacol 1994;37:217-9.

Sagarin BJ, Cialdini RB, Rice WE, Serna SB. Dispelling the illusion of invulnerability: the motivations and mechanisms of resistance to persuasion.J Pers Soc Psychol 2002;83:526-41.

6 Sweet M. Doctors and drug companies are locked in "vicious circle." $B M J$ 2004;329:998.

7 Ogilvy D. Ogiluy on advertising. London: Prion, 1995.
}

Eiganes

Legekontor, St

Olavsgt 9B, N-4005

Stavanger, Norway

Torgeir Gilje Lid

general practitioner

Nedre Movei 35,

$\mathrm{N}-1450$

Nesoddtangen,

Norway

Rune Eraker

photographer

Section for General

Practice,

Department of

Public Health and

Primary Health

Care, University of

Bergen, Kalfarveien

31, N-5018 Bergen,

Norway

Kirsti Malterud

professor

Correspondence to:

T G Lid

giljelid@online.no

BMJ 2004;329:1488-90

\section{"I recognise myself in that situation ..." Using photographs to encourage reflection in general practitioners}

Torgeir Gilje Lid, Rune Eraker, Kirsti Malterud

Photographs can elicit strong emotions and encourage reflection, but what effect can such self reflection have on a general practitioner's identity?

\section{Photography is a tool for dealing with things everybody knows about but isn't attending to. \\ Emmet Brown, photographer ${ }^{1}$}

Doctors' skills in communication have received much attention lately, yet there is still a need for general practitioners to develop a more profound self awareness, not just of their clinical skills but of their professional identity as a doctor. ${ }^{23}$ Images can help elicit memories, feelings, and conflicts forgotten or perhaps never acknowledged. ${ }^{4}$ We developed a photography based strategy to facilitate and stimulate reflections on clinical practice and on what it means to be a general practitioner.

\section{Materials and methods}

\section{The photography}

We chose four general practitioners as models to cover both sexes and different nationalities, ages, and practice location. The photographer spent five to eight days with each doctor, capturing encounters with patients in the practice, on call, in nursing homes, and at a child health centre. He was given few instructions but was briefed to focus on the doctor and on the interaction with patients. No artificial light was used, and the photographer never attempted to rearrange a situation. The patients were informed of the study in writing and gave their oral consent to the doctor before their consultation. They were shown the images, and their permission was obtained to have them reprinted.

\section{The reflective strategy}

The reflective strategy was developed on the basis of experiences and discussions in three groups. ${ }^{5}$ To test

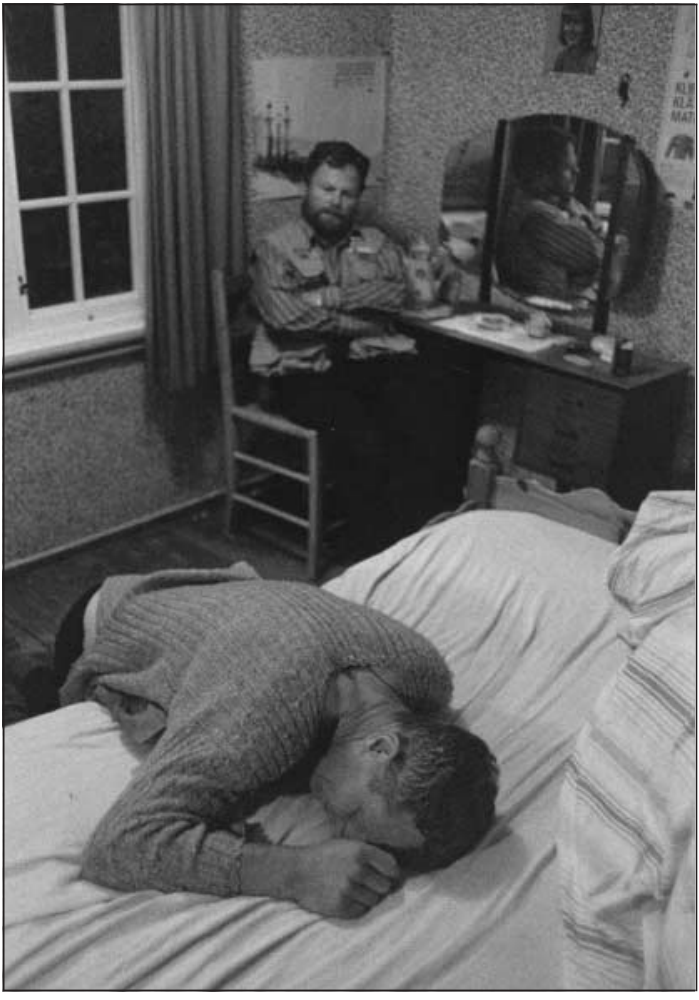

"That you can learn something ... especially when it comes to those enclosed settings, where usually no one sees the hand you've been dealt"

the strategy, one researcher (TGL) selected photographs on the basis of his judgment of the tension in 